\title{
О ФЕДОРЕ ИВАНОВИЧЕ ДУБОВИЦКОМ
}

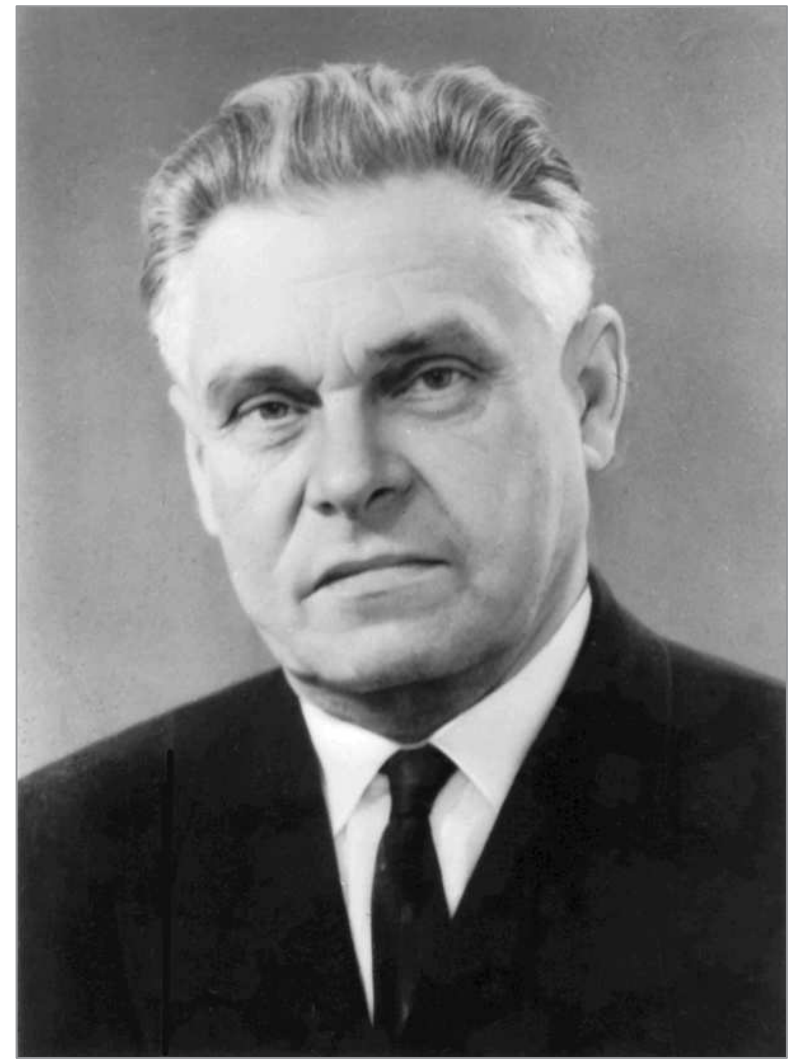

(1907-1999)

Дубовицкий Федор Иванович - член-корреспондент Российской академии наук, выдающийся организатор науки - один из основателей Филиала Института химической физики в Черноголовке (ныне Институт проблем химической физики РАН), Научного центра в Черноголовке, первый директор Московского физико-технического института, ученый в области химической физики горения и взрыва. Он уделял огромное внимание оборонным исследованиям, разработке и изучению новых энергонасыщенных соединений, твердых ракетных топлив, взрывчатых составов и порохов.

За участие в создании и внедрении в оборонную промышленность высокоэнергетических смесевых твердых ракетных топлив и их уникальных компонентов, мощных взрывчатых веществ (BВ), составов на их основе он удостоен двух Государственных премий (1970 и 1986 гг.), премии Совета Министров СССР (1981 г.), награжден орденами Ленина (1975 г.), Октябрьской Революции (1981г.), Трудового Красного Знамени (1967 г.), «Знак Почета» (1945 г.) и «За заслуги перед Отечеством IV степени» (1997 г.).

Федор Иванович Дубовицкий - один из ближайших учеников и соратников лауреата Нобелев- ской премии по химии, академика Н. Н. Семёнова. В Институт химической физики он пришел аспирантом в 1931 г. после окончания Воронежского университета. Будучи прекрасным экспериментатором, он участвовал в опытном обосновании теории разветвленных цепных химических реакций. В частности, именно он открыл явление холодных пламен. Проявив себя также талантливым организатором, уже в 1937 г. он стал заместителем директора института.

В дальнейшем основным направлением научной деятельности Ф. И. Дубовицкого стало исследование процессов горения ВВ и кинетики их термического разложения.

Трудно переоценить ту роль, которую он сыграл во время войны в качестве организатора эвакуации ИХФ в г. Казань, жизни и деятельности Института в казанский период, при переезде Института в Москву, в послевоенный и последующий почти сорокалетний период его деятельности как руководителя. Совместно с директором ИХФ Н. Н. Семёновым ему пришлось заниматься приоритетными научными и научно-организационными делами института и, в первую очередь, проектами, имеющими оборонное значение. 


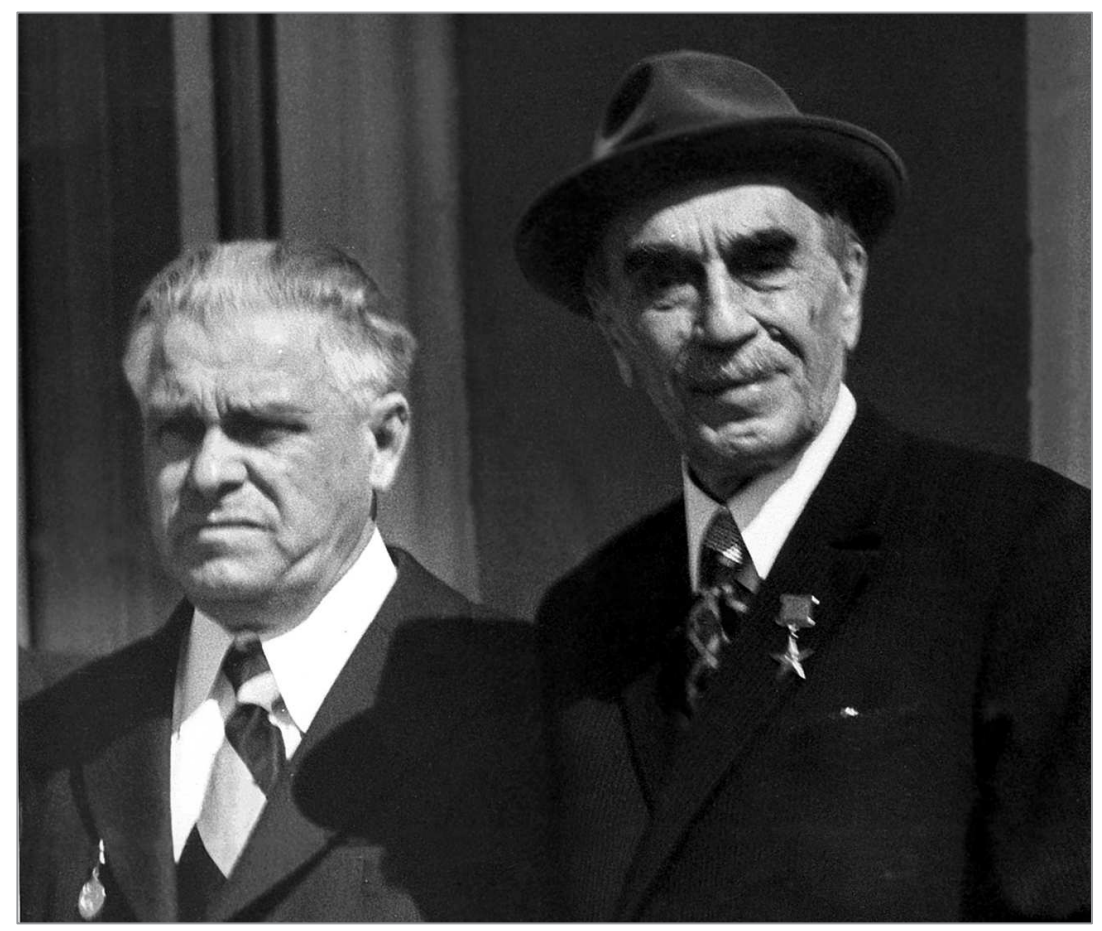

Академик АН СССР Н. Н. Семёнов и член-корреспондент АН СССР Ф. И. Дубовицкий

На всех этапах своего развития ИХФ АН СССР принимал самое активное участие в решении важнейших оборонных и народно-хозяйственных проблем страны, и Ф.И. Дубовицкий был здесь одним из первых. В конце 1940-х гг. он открыл степенной закон зависимости скорости горения конденсированных систем от давления, закон, без которого сейчас невозможно представить создание твердых ракетных топлив.

Известен огромный вклад ученых всемирно известной Семеновской научной школы химической физики в создание ядерного оружия России. Ученики Н.Н. Семёнова академики Ю. Б. Харитон, Я. Б. Зельдович, член-корреспондент К. И. Щёлкин трижды были удостоены звания Героя Социалистического Труда. Десятки сотрудников ИХФ получили Государственные премии и высокие награды за работы в 1946-1963 гг. В воспоминаниях академика Ю. Б. Харитона, главного конструктора советского ядерного оружия, имеются следующие строки: «В 1940 г. Н. Н. Семёнов обратился с письмом в Наркомат нефтяной промышленности, К которому тогда относился наш институт. В письме высказывались соображения о необходимости серьезного развития работ (по урановому, атомному проекту - aвm.), которыми мы с Я. Б. Зельдовичем занимались. Он направил письмо и одного из сотрудников ИХФ с хорошими организационными способностями - Ф. И. Дубовицкого, в Наркомат с тем, чтобы способствовать развитию этого направления. К сожалению, результатов не было». Если бы это обращение Н. Н. Семёнова было должным образом воспринято, то создание ядерного оружия в СССР и в мире, безусловно, пошло бы по иному сценарию.

В 1958 г. в составе отдела горения конденсированных систем была создана лаборатория кинетики разложения взрывчатых веществ под руководством Ф. И. Дубовицкого. Еще до этого Ф. И. Дубовицкий сделал важное открытие. Он обнаружил резкий скачок скорости термического разложения ВВ в области их температуры плавления. Это явление помимо несомненного научного значения очень важно для практики, поскольку позволяет корректно оценивать термическую стабильность энергоемких систем. В лаборатории Ф. И. Дубовицкого детально изучался механизм термического разложения взрывчатых материалов, создавались кинетические методы оценки химической стабильности и методики расчетов сроков длительного хранения как индивидуальных ВВ, так и порохов, твердых ракетных топлив и взрывчатых составов на их основе.

Исследование кинетики распада ВВ привело его лабораторию к постановке работ по изучению взрывчатых свойств новых мощных ВВ и созданию методов прогнозирования критических условий теплового взрыва при технологии изготовления и в условиях длительного хранения зарядов. Эти 


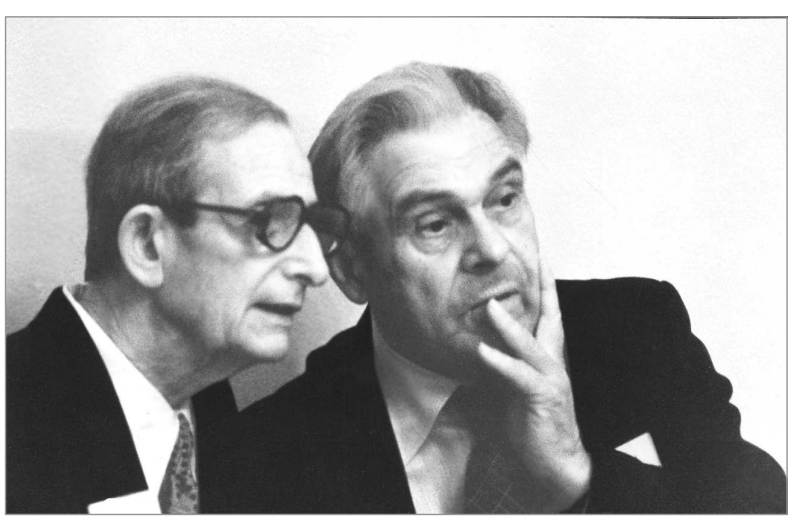

Академик АН СССР Ю. Б. Харитон и член-корреспондент АН СССР Ф. И. Дубовицкий

кинетические исследования с участием Г. Б. Манелиса, Ю. И. Рубцова, Г. М. Назина, А. Г. Мержанова, В. Г. Абрамова, В.В.Барзыкина, Л. Т. Еременко привели к активному развитию химической физики горения и взрыва, способствовали внедрению новых мощных ВВ в практику.

Большой объем исследований в Институте проводился по линии Военно-промышленной комиссии при Совете Министров СССР. Федор Иванович Дубовицкий, не только принимал самое активное участие в создании и разработке новых современных высокоэнергетических твердых ракетных топлив, но и являлся заместителем председателя научного совета АН СССР по твердым ракетным топливам, которым изначально руководил академик А. В. Топчиев, а затем академик Н. Н. Семёнов. Занимая эту должность, Ф. И. Дубовицкий фактически курировал все работы по твердым ракетным топливам, проводимые в Академии наук.

В те годы проводились фундаментальные исследования в области конвективного горения применительно к проблематике метательных блочных пороховых зарядов. Широким фронтом в тесном сотрудничестве ИХФ с Институтом органической химии АН СССР выполнялись синтетические исследования в области новых химических ВВ и составов на их основе. Федор Иванович Дубовицкий, находясь в постоянном взаимодействии с Военнопромышленной комиссией при Совете Министров СССР и ее научно-техническим советом, являлся одной из центральных фигур в АН СССР, которые обеспечивали координацию и взаимодействие ее институтов с предприятиями оборонной промышленности.

Федор Иванович Дубовицкий обладал редким даром разглядеть в молодом сотруднике способного талантливого ученого и сделать все возможное, чтобы создать условия для его плодотворной работы. Среди тех, кого активно поддержал и во многом обеспечил развитие их научно-технических направлений - известные в стране и мире ученые: академики А. Г. Мержанов, Ю. М. Михайлов, В.Е. Фортов, член-корреспондент РАН Г.Б. Ма-

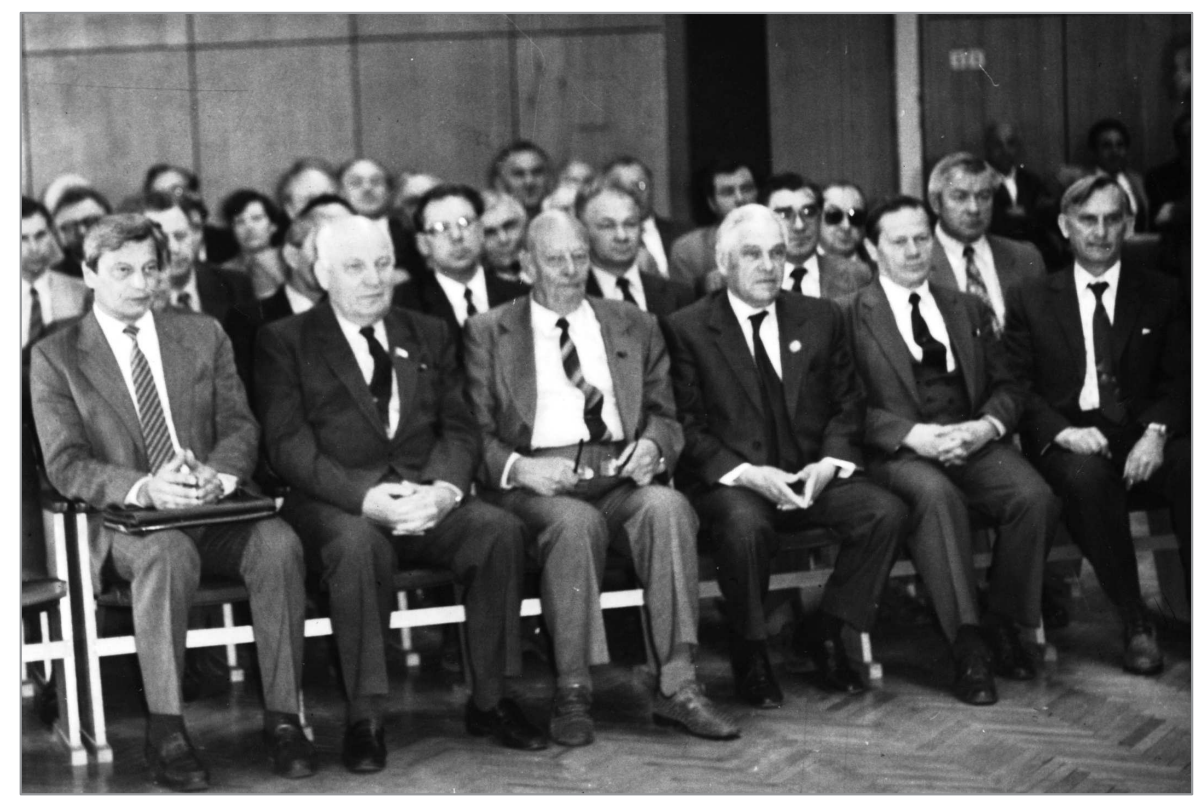

Выездное заседание коллегии Министерства машиностроения СССР в отделении ИХФ (Черноголовка) с участием президента АН СССР, академика А. П. Александрова (слева направо: зам. министра Л. В. Забелин, министр машиностроения В. В. Бахирев, президент АН СССР А. П. Александров, директор ОИХФ АН СССР Ф. И. Дубовицкий, зам. нач. отдела ВПК при Совете Министров СССР Макаров Е. В., директор ЛНПО «Союз» Жуков Б. П. 
нелис, профессора Ю. А. Гостинцев, Б. Л. Корсунский, А. Д. Марголин, А. А. Сулимов и многие другие.

Выдающимся достижением в научно-организационной деятельности Ф.И. Дубовицкого безусловно было создание Филиала ИХФ АН СССР в п. Черноголовка и Научного центра на его основе. Теперь это город, ставший наукоградом, центральная площадь которого названа именем Ф.И. Дубовицкого. На этой площади установлен памятник основателям нынешней Черноголовки Н. Н. Семёнову и Ф. И. Дубовицкому. Здесь, в Черноголовке, Федор Иванович провел свои лучшие

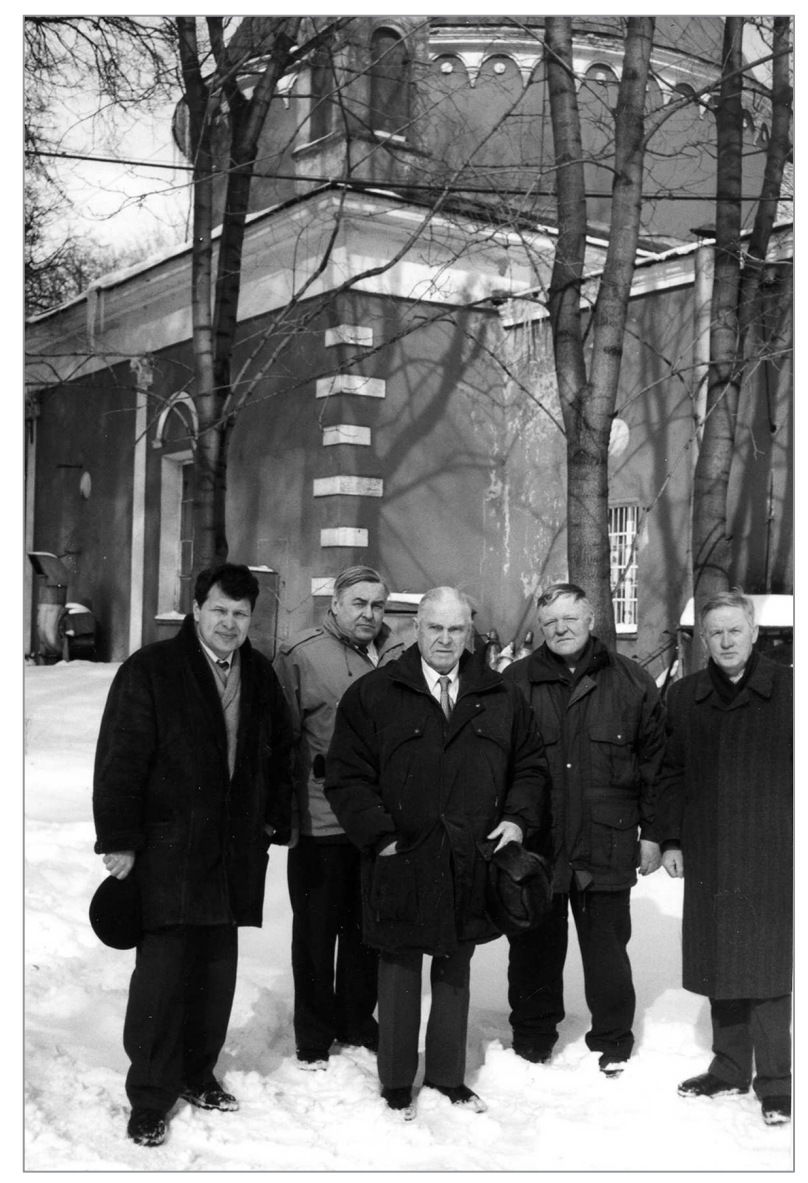

1995 г. Член-корреспондент АН СССР Ф. И. Дубовицкий с сотрудниками на фоне первой в СССР взрывной камеры ИХФ, построенной в 1948 г. под руководством Ю. Б. Харитона и А.Ф. Беляева (слева направо: проф. Ю М. Михайлов, к.ф.-м.н. В. Ф. Дубовицкий, член-корреспондент РАН Ф. И. Дубовицкий, Е. А. Мосалев, проф. А. А. Сулимов

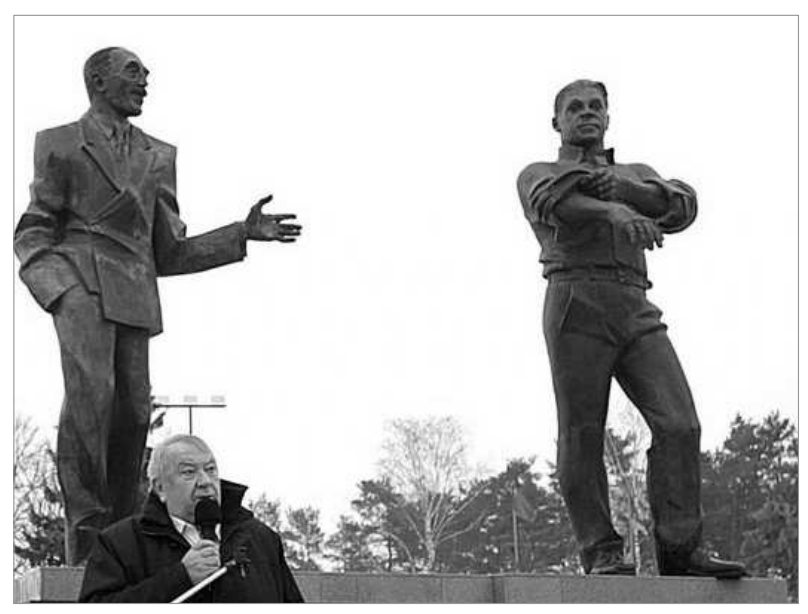

Памятник Н. Н. Семёнову и Ф. И. Дубовицкому в г. Черноголовка

творческие годы ученого, воспитателя научных кадров, организатора на научном и научно-техническом поприще. Здесь же, освободившись от повседневных забот, он написал свой капитальный труд «Институт химической физики (очерки истории)». В книге, изданной в 1992 г. (второе издание в 1996 г.), более 200 очерков - по числу лабораторий в едином, еще не разделенном ИХФ. Главная задача, как отмечал автор, заключалась в том, чтобы познакомить широкие круги читателей с жизнью и деятельностью ученых, инженеров, техников, в коллективе, насчитывающем 5000 сотрудников, показать его достижения и условия, в которых проходила работа. Это было связано с определенными трудностями, потому что нужно было по возможности в коротком очерке сообщить о каждом ученом, руководимой им научной лаборатории, описать сущность научного направления и его значение в науке.

В 2016 г. в Москве недалеко от Московского физико-технического института, одним из основателей которого он был, появилась улица Федора Дубовицкого.

Научная компетентность, искренняя доброжелательность, простота, умение общаться с людьми и стремление помогать им снискали Ф.И. Дубовицкому высокий авторитет и уважение не только среди сотрудников Института проблем химической физики РАН, Института химической физики РАН, институтов Научного центра Российской академии наук в Черноголовке, но и многочисленных коллег в оборонных институтах.

Ю. М. Михайлов, Б. Л. Корсунский, А. А. Сулимов 